\title{
QUILOMBO, TERRITÓRIO E GEOGRAFIA
}

Lourdes de Fátima Bezerra Carril ${ }^{1}$

1.carril@uol.com.br

\section{RESUMO:}

Este artigo analisa a autoidentificação do quilombo por comunidades rurais no vale do Ribeira, na luta pelo acesso à terra, ancorada no artigo 68 da Constituição Brasileira, que garante o direito às terras de quilombos, no Brasil. A análise se estende ao fato de que comunidades de rappers, bem como outros moradores da periferia de Capão Redondo, em São Paulo, também vêm chamando para si a auto-identidade de quilombolas e para esses espaços da cidade, de quilombos. Procura-se entender que essa representação expressa, tanto a exclusão da terra no campo, como a segregação social, espacial e racial na cidade. Liga-se às relações desiguais e contraditórias, historicamente, presentes na constituição sociedade-território no Brasil. Em ambos os casos, os grupos buscam uma identidade comum. A identificação e a representação do quilombo torna-se base para a sobrevivência física e cultural, significando também a tentativa de reenraizamento social e espacial ou de criação de uma nova territorialidade, a inserção social pelo rap e a recuperação da autoestima.

Palavras-chave: Quilombo, identidade, território, territorialidade, segregação, sócioespacial e racial, confinamento, relação sociedade-território.

\section{ABSTRACT:}

This paper analyses the autoidentification of quilombo by country comunnities in the Vale do Ribeira, in the struggle for land access, under the light of the Brazilian Constitution 68 article, which secure the right of property for quilombo lands in Brazil. The analysis scope goes through the fact that rapper communities and other people that lives in Capão Redondo perifery in São Paulo, are assuming for themselves the autoidentification of quilombolas and calling those city spaces Quilombos. The attempt is to understand that

\footnotetext{
${ }^{1}$ Mestre em História Social e Doutora em Geografia pela Faculdade de Filosofia, Letras e Ciências Humanas, da Universidade de São Paulo - USP e Professora do Centro Federal de Educação Tecnológica de São Paulo (CEFET/SP).
} 
this representation express both the exclusion for the country lands and social, spacial and racial segregation. This is related with non-equal and contraditory relations, historically present in Brazilian society/territory constitution. In both cases, the groups looks for a common identity. The identification and quilombo representation became basis for physical and cultural survival, also meaning the atempt for reconstruction of social and spacial roots or the creation of a new territoriality, the social insertion through the rap and self-respect.

Key words : Quilombo, identity, territory, territoriality, segregation, socio-spacial and racial, confinement, society-territory relationship 
Não é discutir o que foi, e sim discutir o que é e como essa autonomia foi sendo construida historicamente. (A. W. B. de Almeida)

$\mathrm{Na}$ atualidade, a diversidade da luta pela terra e pela cidadania no Brasil instiga a refletir sobre as categorias presentes no quadro de uma exclusão social histórica com implicações etno-raciais. Nesse sentido, a própria categoria conceitual camponês não abrange as diferentes realidades que compõem a relação com a terra no campo e nem a marginalização urbana se apresenta somente como recorte de classe social, mas ambas realidades, construídas pela definição do acesso à propriedade e da forma como a modernização se realizou, no Brasil, apontam para uma linha de exclusão racial. A proposta deste artigo é analisar a representação quilombola expressa por grupos presentes na cidade e no campo, pensando a questão do território, na perspectiva geográfica das dinâmicas historicamente em movimento de segregação espacial e racial e resistência territorial.

As formas de uso da terra e dos recursos do território têm mostrado que o acesso à terra apresenta demandas historicamente construídas nas quais a questão do trabalho e as estratégias de sobrevivência vêm se colocando como aspectos de crucial importância para a definição de um traçado de lutas existentes no Brasil. Mas, a questão conclama a pensar o processo da exclusão considerando a questão racial, que traz a problemática também para o urbano.

Na perspectiva de Almeida (2002:53), como processo histórico que trouxe aos indivíduos de um grupo a autoidentificação de quilombos, significa pensar a questão da identidade como elemento central para a reafirmação da condição de ser e viver um lugar, nesse caso, um território.

As lutas pelas terras de quilombos e as lutas dos movimentos negros urbanos pressionaram o trabalho da Constituinte de 1988, aprovando o Artigo 68 que garante o direito às terras de quilombos e positiva um passado de luta, retornando para que esses grupos possam criar novos espaços políticos na sociedade brasileira. Essas conquistas somente se tornam possíveis através da materialização de sua história e cultura vinculadas ao território, no caso rural. E no espaço urbano? 
O estudo dos quilombos no vale do Ribeira nos chamou a atenção sobre a identificação étnica de uma parte dos camponeses no Brasil que, frente às pressões sócioeconômicas, refazem o processo histórico, remetendo-o à escravidão e à busca da história da ocupação das terras. Agora, grupos localizados nas periferias de São Paulo identificam também essas partes da cidade como quilombo:

"A que sentido foi, eles prometeram um mundo novo, favela, viela, morro, tem de tudo um pouco, tentam alterar o DNA da maioria, rei Zumbi, antigamente quilombos, hoje periferia, levante as caravelas, aqui não daremos trégua, não, não, então que venha a guerra....." (Z'África Brasil)

Para realizar uma discussão acerca da identidade quilombola este trabalho se divide em três partes, na primeira, vamos falar sobre a nossa trajetória de pesquisa sobre quilombos, a segunda, tratará da identidade quilombola e a terceira sobre quilombo e território.

\section{A pesquisa}

Começamos a pesquisa com os quilombos de Ivaporunduva, Pilões e Sapatu, no vale do Ribeira, no mestrado que desenvolvemos em História Social, na FFLCH/USP.

Muitos dos quilombos permaneceram nos mesmos sítios ou próximos de onde eles se formaram desde a época da escravidão, praticando a agricultura de excedentes comercializáveis, mantendo relações comerciais com os mercados próximos ou com os comerciantes que passavam próximo aos sítios onde estavam localizados. As formas de apropriação dos recursos naturais foram, na maioria das vezes, resultado da interação com o ambiente em que se encontraram na medida em que as famílias se refugiaram em áreas de florestas e matas, a montante de cachoeiras ou em serras. No vale do Ribeira, a presença de remanescentes de Mata Atlântica propiciou a prática do extrativismo, como a extração do palmito e a existência de terras abundantes e livres forneceu as bases, seja para a autosobrevivência ou para a comercialização, bem como para a reprodução física e cultural desses grupos e seus modos de vida. 
As comunidades de quilombos no vale do Ribeira permanecem nas terras por mais de um século. $\mathrm{O}$ fato de que a maioria das terras no vale ter permanecido, em grande parte, devoluta até a década de oitenta, implicou em conflitos fundiários que se acentuaram com os projetos modernizadores colocados em prática na região. Além de projetos de barragens para o rio Ribeira de Iguape (CBA - Companhia Brasileira de Alumínio), a partir do qual se estruturou um movimento social para impedir a sua construção, o estabelecimento de unidades de conservação trouxe impactos sobre as comunidades.

Até a década de oitenta, do século XX, a situação dominial ainda não havia sido regularizada no vale, que continha uma área de, aproximadamente, 1,5 milhão de hectares; calcula-se que em torno de 700 mil hectares eram terras devolutas - terras sob domínio público, mas em contrapartida nelas, implantaram-se várias unidades de conservação. Dos $13.000 \mathrm{~km} 2$ dos remanescentes de Mata Atlântica, cerca de $8.350 \mathrm{~km} 2$ estaria no vale do Ribeira. Em 1985, as restrições legais impediam o uso de 75\% das terras do vale.(CARRIL1995).

Dona Antonia, uma senhora já falecida da comunidade de Pilões (localizada na APA da Serra do Mar) explicava:

“O governo não deixa roçar, plantar a restinga no mato.. a gente não carecia comprar as coisas do jeito que estão caras...planta lá no sertão escondido e às vezes paga multa, plantam arroz, milho, mandioca, banana...só pode plantar perto de casa, senão tem que plantar escondido...o filho meu fez uma roça, arroz, milho, mandioca, batata, couve... agora o mato cresceu e a terra enfraqueceu e não dá mais nada..."2

A concepção de áreas protegidas, implantada nos países do Terceiro Mundo tem se baseado na idéia de terra vazia e intocada. O modelo de parque e reservas foi importado dos E.U.A. e tem como principal objetivo preservar áreas de interesse ecológico e de manutenção de ecossistemas.(DIEGUES:1994:11)

Os quilombos desenvolveram uma relação específica com a natureza, de escravos eles se transformaram em camponeses. O relacionamento humano com a terra tornou-se fundamental como meio de sobrevivência na sociedade escravista. Viver nos quilombos equivalia a arar e cultivar a terra para dela extrair os recursos necessários à vida e também

\footnotetext{
${ }^{2}$ Entrevista realizada, em nossa pesquisa, em 1994.
} 
dela fazer sua moradia e nela reconstruir seu suporte cultural, numa perspectiva de autosobrevivência.

Em certos ecossistemas, como os de floresta, os quilombolas tornaram-se extrativistas. Habitantes das margens de rios tornaram-se ribeirinhos e pescadores, além de agricultores, no interior das matas, à montante das cachoeiras e nas serras, lugares que serviram de abrigo e esconderijos, protegendo-os dos capitães do mato. As simbologias e representações sobre a natureza formuladas pelos quilombos originaram a base da identidade homem-meio. Memória, terra e etnia formaram uma simbiose que thes permitiram um vínculo duradouro entre si e com o lugar. Permanecer nessas terras após alguns séculos revela-se uma vitória histórica numa sociedade camuflada pelo "mito da democracia racial". Num sistema sócio-econômico-político e territorialmente excludente, a luta pela terra nos quilombos é, de um lado, uma fração da luta pela reforma agrária e de outro, uma tentativa de reparar parcialmente a histórica exclusão social do negro brasileiro, no tocante a comunidades com identidades próprias.

Esse conjunto de considerações e de fatos apresentados nos convida a participar do debate sobre a relação sociedade-natureza atualizado aqui pelos quilombos, pelas políticas públicas e pelas modalidades de tratamento da natureza nos últimos anos, a partir também das teorias e das políticas ambientais. Através da forma específica e exemplar da presença dessas comunidades no meio rural e no meio urbano, pode-se refletir sobre a visão predominante, nos últimos anos, na maioria dos modelos de conservação a ela associada, sobre os novos conceitos de biodiversidade, populações tradicionais e desenvolvimento sustentável.

Muitos conflitos estão atrelados à relação sociedade-território e, conseqüentemente, problemas sociais foram criados e acentuados, no Brasil, em decorrência da formação territorial, na qual predominou a idéia de modernização sem inclusão social e em que se insere também uma visão de proteção da natureza, implicando, muitas vezes, no condicionamento do modo de vida de populações nas áreas onde houve a criação de parques.

Na pesquisa de doutorado em geografia foi estudado o teor quilombola expresso no bairro de Capão Redondo, a partir das letras de rap e realizadas entrevistas em três bolsões 
de pobreza: o CDHU, a Cohab Adventista e Favela de Paranapanema, além de entrevistas com estudantes do cursinho pré-vestibular afrodescendente Dandara.

Conceitos como quilombo, senzala e casa-grande fazem parte do cotidiano de jovens da periferia da maior e mais rica cidade do país. Em nossa pesquisa com moradores do distrito do Capão Redondo, na periferia da zona sul, de São Paulo, constatamos que, alguns deles - sobretudo os que gostam e fazem rap, comparam as relações sociais e espaciais da cidade com uma senzala.

No rap, o quilombo é resgatado da imagem da figura de Zumbi dos Palmares. O quilombo parece ressurgir e seu conceito se ampliar a partir de várias realidades, indicando que os temas da escravidão, da discriminação racial e da resistência negra permanecem no imaginário social e na materialidade da vida social brasileira ainda neste início de século.

O objeto principal de nosso trabalho - quilombos rurais e quilombos urbanos mostra bem os termos dos desafios apresentados pelo tema aqui proposto, porque desde as terras de santos até os quilombos conhecidos como lugares comunitários tradicionais, estes eram identificáveis. Os negros se reconhecem como comunidade negra para si, parafraseando Darcy Ribeiro ao tratar da questão indígena, e, assim, também são reconhecidos em seu entorno. Logo, trata-se de diferenças étnicas claramente demarcadas, socialmente aceitas e até juridicamente estabelecidas. $\mathrm{O}$ que o reconhecimento da autoidentificação de quilombo no bairro do Capão Redondo e em outros bairros trouxe como uma nova dimensão para esse desafio? Encontrar nesses espaços urbanos contingentes humanos que reivindicam a negritude, atribuem uma correlação entre periferia e quilombo, e por isso vão tocar o tema de uma outra forma, mas com que pertinência? Ficou mais claro, com o tempo que, para os quilombos de ocupação tradicional, o uso dos recursos naturais coincidia com o seu modo de vida e, portanto, com a sua interação comunitária com o meio e sua cultura.

O desafio posto pelo mesmo diálogo quanto aos agrupamentos recentes nos espaços urbanos parte de grupos que se reivindicam da mesma origem e chamam a atenção ao problema das dívidas históricas. Porém, às vezes, eles localizam-se em espaços inconvenientes para o conjunto da cidade, como os mananciais, sem uma tradição cultural de respeito à natureza encontrada nos quilombos rurais. 
Essas considerações sobre quilombos, o meio e a cultura, exigem uma pesquisa própria - o desafio do diálogo entre geografia e outras ciências, com respostas necessariamente novas e este trabalho traz a comparação entre o quilombo rural e o urbano, recorre à teoria social, temas antropológicos, de outras óticas como o tema da exclusão urbana, da identidade étnica em suas diversas formas, do estudo da natureza, e das diferentes formas, de relação com a natureza e com o mercado. O quilombo rural produz excedentes para o mercado, o urbano, mão-de-obra barata, exército de reserva e não conta com o mecanismo regulador cultural da defesa do meio ambiente que nós encontramos tradicionalmente.

O quilombo rural ressurgiu como identidade reconstruída (Cunha, 1987) a partir do passado comum. A constatação da escassez no rural, verificada principalmente pelos mais velhos, foi possível mediante a comparação entre um passado de abundância e alegria cooperativa pós-escravidão e as carências visíveis do presente. O quilombo urbano surgiu da organização em torno de uma nova estética e estilo de manifestação político-cultural de protesto, típicos dos guetos negros norte-americanos, como o Hip Hop. (Rocha, Domenich e Casseano, 2001).

A condição de ser negro contém novas possibilidades como pertencer a um grupo antigo, a uma ancestralidade ou a tradição cultural. O quilombo parece prometer a possibilidade de garantir a terra, a comunidade e a auto-estima. Uma nova identidade? $\mathrm{O}$ tema territorialidade no urbano indica menos terra comunitária nos lugares de encontro e mais manifestações culturais auto-identificadas.

\section{Quilombos e identidades}

Quando estudamos as comunidades remanescentes de quilombos no vale do Ribeira, chamava a nossa atenção o fato de que no fim do século XX pudéssemos encontrar relações comunitárias de grupos étnicos com sobrevivências culturais presentes na prática e na memória viva dos mais velhos, integrando o universo rural brasileiro.

O tema quilombo como todo tema ligado à diversidade cultural ou às culturas consideradas tradicionais, como são: o indígena, o ribeirinho, os jangadeiros, as comunidades litorâneas e os de outras comunidades tradicionais, convida, e, sobretudo, no 
campo da geografia, a uma relação específica quanto ao uso diferenciado dos recursos naturais, e, freqüentemente, na contramão daquele que a sociedade dominante empreende ao apropriar-se dos mesmos recursos.

A complexidade apresentada pelo estudo de quilombos se estende por diferentes campos do saber e especialistas. Em primeiro lugar, vale destacar que a retomada de debates sobre o tema resulta de uma série de trabalhos, recentes, como monografias, teses e publicações nascidas na antropologia, no direito e, posteriormente, na história, onde desenvolvemos a nossa dissertação de mestrado ${ }^{3}$.

Mais recentemente chamou a atenção da mídia e dos especialistas o surgimento de agrupamentos urbanos auto-identificando-se como quilombolas, experimentando uma expressão cultural própria e diferenciada no entorno das grandes metrópoles, a exemplo e com influências de fenômenos semelhantes norte-americanos, como nos casos do Hip-Hop e Funk, assumidas abertamente como revolta da negritude excluída em suas publicações e escritos. Estas formações sociais, e até por serem formas novas de uma mesma antiga revolta, exigem ser compreendidas e explicadas, inclusive no plano comparativo com os quilombos rurais tradicionais.

Do ângulo da geografia e da interdisciplinaridade, dá-se também a coincidência de que a localização destes quilombos "culturais" urbanos seja, como os rurais, embora de forma diversa, pontos sensíveis da relação sociedade-natureza, - como no estudo de caso selecionado para este trabalho (região de Campo Limpo/São Paulo/SP). Como os espaços menos disputados pela especulação imobiliária foram os pontos da periferia onde se concentram os excluídos, ali irão defrontar-se, inclusive estas manifestações quilombolas citadas, com os desafios da preservação dos mananciais e dos raros redutos florestados das metrópoles frente a políticas ambientais que excluem o uso nas áreas de proteção.

Empurrados para as áreas extremas da metrópole, configurou-se uma segregação espacial e racial em São Paulo. A falta de emprego, a criminalidade e ausência do poder público, inclusive com deterioração da qualidade da escola pública impõem a esses territórios da cidade o imaginário social de lugares perigosos, de marginalidade e exclusão.

\footnotetext{
${ }^{3}$ Carril, L. F.B. Terras de Negros no vale do Ribeira: Territorialidade e Resistência. Dissertação (Mestrado) apresentada ao Departamento de História da FFLCH/ US.P. SP, 1995.
} 
Uma espécie de confinamento territorial que se assemelha ao gueto norte-americano, o que se explicita nas letras do rap.

Desde a década de cinqüenta, alguns estudos das ciências sociais vêm trazendo a questão de que os quilombos não se restringem ao período escravista. Vários agrupamentos de população negra foram identificados em distintas regiões brasileiras, sobretudo em lugares mais afastados dos centros urbanos e das regiões industrializadas do país, como lugares de refúgio. Muitos deles guardavam saberes tradicionais, manifestações culturais próprias como dialetos e relação específica com a natureza, bem como respeito a valores da ancestralidade pertinente à formação do grupo.

A identificação de quilombos no meio rural do Brasil contemporâneo fez rever a conceituação tradicional como fuga e resistência escravista, porque as pesquisas trouxeram à luz que a formação desses agrupamentos ocorreu também por outras vias como doações de terras, por abandono dos escravos pelos senhores e por terras doadas a santos. Esta diversidade se revelou, também, no momento em que se iniciaram as tentativas de titulação dessas terras amparadas pelo Artigo 68 das Disposições Transitórias da Constituição de 1989.

A diversidade das formas de constituição das terras de quilombos, e este é o segundo aspecto da questão, propiciou a retomada de discussões e pesquisas sobre o conceito de quilombo. Moura ${ }^{4}$ aponta a definição de quilombo conforme o que determinou o Conselho Ultramarino de 1740, segundo o qual, quilombo era "toda habitação de negros fugidos que passem de cinco, em parte despovoada, ainda que não tenham ranchos levantados nem se achem pilões neles".

A definição do Conselho Ultramarino tornou jurídica a questão das fugas de escravos, baseando-a na noção de escravos fugitivos, mas a realidade territorial dos quilombos no período atual nos leva a identificar outras origens, ou processos formativos quilombolas, tornando-se um obstáculo conceitual e interpretativo à implementação daquele artigo constitucional. A constatação de várias e diversas origens de quilombos no Brasil nos apresenta um campo de discussão sobre a identidade e a territorialidade.

Historicamente, podemos verificar que não houve um tratamento da questão do negro brasileiro por parte do governo e das instituições. A Igreja Católica deixou lacunas

\footnotetext{
${ }^{4}$ MOURA, C. Os quilombos e a rebelião negra. Tudo é História. São Paulo: Brasiliense, 1981.
} 
quando envolvia a problemática do escravo africano na sociedade brasileira e mesmo houve em alguns de seus setores a utilização dessa mão-de-obra. Quando houve a abolição, também não existiu uma preocupação por parte do Estado em ressarcir ou proteger o exescravo, como foi feito a partir da legislação com os indígenas (caso das reservas indígenas).

Constata-se, mesmo quando com reservas, comparativamente com outras instituições coloniais, uma tradição de maior coerência por parte dos jesuítas e de outros setores eclesiásticos na defesa dos direitos indígenas, superior a que foi dedicada aos negros. É verdade que mais tarde a Igreja passa a reconhecer terras de santos ou terras de doações que não vieram apenas da Igreja, mas também de proprietários que concederam parcelas de suas terras a libertos antes mesmo da Lei Áurea, devido à decadência da economia, conflitos, reparações ou dívidas de relações de concubinato.

Nesta pesquisa, o desafio que se põe para o diálogo entre as geografias é que hoje obrigatoriamente deve-se colocar uma interdisciplinaridade ainda mais ampla, pois o tema revela várias faces da realidade. A face mais integradora é a de que os usos dos recursos são realizados com base na relação homem-meio e é onde permeiam distintas ações, que são políticas, mas são também culturais e étnicas. As formas de territorialização, desterritorialização e reterritorialização desses grupos colocam para nós o contínuo processo de desconstrução e reconstrução das identidades territoriais presentes na sociedade brasileira dadas pela migração e pela perda de meios de vida. É este o nosso caminho metodológico de investigação da pesquisa aqui apresentada.

Vários movimentos sociais tiveram início entre os quilombos rurais, com apoio de partidos políticos, movimentos negros, movimentos ambientalistas, e, sobretudo, a Igreja, para que através da titulação da terra, o homem não se separe do meio. Entre os quilombos urbanos, a organização se faz entre os homens em torno da música, da dança e da arte, ali onde o meio lhe é hostil. No urbano, não se planta, não se pesca e nem se coletam frutos da mata. Na cidade fragmentada, os grupos se solidarizam para recuperar a auto-estima em situação de marginalização social.

A identidade é construída na luta e na escassez, e é este um dos fatores que unifica o quilombo rural e o quilombo urbano. É o que aponta Manuela Carneiro da Cunha

\footnotetext{
${ }^{5}$ CUNHA, M C. Antropologia do Brasil. Mito. História. Etnicidade. São Paulo: Brasiliense, 1987.
} 
“A cultura original de um grupo étnico, na diáspora ou em situações de intenso contato, não se perde ou se funde simplesmente, mas adquire uma nova função, enquanto se torna cultura de contraste: este novo princípio que a subentende, a do contraste, determina vários processos...A escolha dos tipos de traços culturais que irão garantir a distinção do grupo enquanto tal depende dos outros grupos em presença e da sociedade em que se achem inseridos.”

É o que diz também Milton Santos ${ }^{6}$ quando afirma que os verdadeiros agentes do futuro do país encontram-se entre os que estão sendo excluídos da contabilidade da globalização:

“É também a nação que mantém relações de simbiose com o entorno imediato, relações cotidianas que criam, espontaneamente e na contracorrente, uma cultura própria, endógena, resistente, que também constitui um alicerce, uma base sólida para a produção de uma política. Essa nação mora ali onde vive e evolui, enquanto a outra apenas circula, utilizando os lugares como mais um recurso a seu serviço, mas sem outro compromisso".

A dona Antonia Vitorino de Oliveira (1905-1995), do quilombo de Pilões, no vale do Ribeira dizia:

“Pode trabalhar e carpir já que planta dá? Então eu queria que viesse uma libertação no Brasil sabe, porque o Brasil é grande, Brasil não é pequeno lugar, eu desejava que o presidente desse liberdade para o Brasil trabalhar eu não precisava comprar alguma coisa de você, se você não precisa comprar ..., aquela não precisa ta comprando, porque todos nós tinha um punhadinho...."7

\footnotetext{
${ }^{6}$ SANTOS, M. "Nação ativa, nação passiva. Os verdadeiros agentes do futuro do país encontram-se entre os que estão sendo excluídos da contabilidade da globalização" In: "Brasil 500 d.C." - Folha de São Paulo, domingo, 21 de dezembro de 1999. Caderno Mais. Pág. 5-3.

${ }^{7}$ Entrevista realizada na comunidade de quilombo de Pilões, no Vale do Ribeira, em julho/1994, por Carril, L. F. B., durante a pesquisa de mestrado citada.
} 
$\mathrm{O}$ que o tema quilombos rurais e quilombos urbanos apresenta em comum com outras comunidades é a de que em situação de desenraizamento, os membros de um grupo buscam soluções ou formas de inserção social. Neste caso, trata-se de formas de organização sócio-política e cultural com características diferenciadas. No rural, a base territorial é fundamental para a coesão interna e é em torno da territorialidade fixada num ecossistema e até preservando o mesmo que os quilombos lutam para o seu reconhecimento. No urbano, a luta é travada a partir de uma base territorial marginalizada dos investimentos urbanos e nesse contexto, a questão étnica parece responder denunciando a realidade com as letras do rap e com o hip hop, dando visibilidade pública aos grupos e tenta inserir-se no mercado vendendo essas músicas.

\section{Usos do território: problemática territorial quilombola rural/urbana}

O território e seus recursos necessitam de estudos aprofundados frente aos recentes processos de redefinições por que passa o espaço mundial. Ao avançar na direção de um mundo "sem fronteiras" ou com fronteiras mais permeáveis, surge uma nova territorialidade. Esse processo acontece num momento de desmonte das máquinas estatais, desregulamentação e diminuição do campo econômico de ação do Estado. Na América Latina, este quadro é típico, com a redefinição do papel do Estado e a passagem para o setor privado de importantes serviços básicos. Esta situação se agrava se atentarmos para o fato de que essas sociedades não demonstraram, até o momento, força social para enfrentar este novo quadro.

Como abordar o tema etnicidade e a questão da identidade no período atual?

Utilizando as definições de Sack (1986), o viver territorial pelos grupos humanos é o uso da razão e da habilidade que cada um tem para usar o território. Vemos ainda, na linha de pensamento desse autor, que esse processo demarca fronteiras e controle de acesso. A presença do negro nas periferias da cidade não traduz um estar fora (out) do código social (território por convenções)? O rap não seria um código de expressão do comunicarse territorial dos excluídos? Como entender essa problemática? 
Parece-nos indicado que o entendimento dos usos e dos conceitos elaborados com base no vivido territorial só podem ser explicados com base na história da formação territorial. Moraes (2002) aponta caminhos para essa análise, uma vez que a configuração territorial, segundo o autor, pode ser entendida por sua história. Assim como Caio Prado Jr. (1990) em sua História Econômica do Brasil, busca uma explicação do Brasil na colonização e no escravismo, Moraes parece buscar no passado, elementos da formação territorial para compreender o território configurado.

A base territorial em ambos os casos ampara a formação de uma identidade? Tornase base para a sobrevivência da cultura, servindo também para uma tentativa de reenraizamento social e espacial ou de criação de uma nova territorialidade?

Em todos os casos, estamos diante de representações da realidade, na medida em que os seres humanos constroem símbolos e significados sobre si próprios e sobre o mundo. Nesse caminho, o próprio ser individual, o que cada um é aparece como uma idéia, uma categoria ideológica, uma representação social (Brandão, 1986). Isso ocorre, segundo esse autor, no momento em que o homem se torna "representante de suas atuações e o responsável pelos seus atos", ainda na passagem do clã para a vida na pólis, perante a sociedade civil e o Estado. Segundo ele, a questão se estende para os termos de identidade e etnicidade, momentos do viver social.

A teoria social tem se debruçado sobre os temas relacionados à representação, à construção do ser e à identidade. Estas questões aparecem fortemente no período atual, em função de que "as velhas identidades, que por um tempo estabilizaram o mundo social, estão em declínio, fazendo surgir novas identidades e fragmentando o indivíduo moderno, até aqui visto como um sujeito unificado" (Hall, 2001). Fala-se em crise de identidade como conseqüência de abalos sobre os quadros de referenciais antigos.

A situação dos quilombos coloca questões pertinentes ao debate porque, em primeiro lugar, o quilombo rural traduz a sua luta pela terra e através da especificidade étnica, tanto vinculada ao direito territorial como calcada sobre a ancestralidade buscada na origem da conquista da terra. Logo, essa identificação demarca uma diferença no conjunto do campesinato. Por sua vez, a comunidade negra do Hip-Hop expõe em suas letras a situação de exclusão a que está submetida na periferia da cidade de São Paulo. Mas o que 
busca? A exclusão? O incitamento à violência? Parece buscar, pelo contrário, a inclusão na possibilidade simbólica conferida ao Hip Hop.

Por sua vez, não parece suficiente encarar a identificação com a classe, com a história ou com a etnia como processo hegemônico num determinado grupo. Do contrário o ser excluído seria condição absoluta da consciência, o viver na periferia seria condição da exclusão ou o ser pobre engendraria estratégias conjuntas entre brancos e negros e entre negros e negros na cidade. Há entre essas esferas, uma série de mediações, das quais a representação, a ideologia e a identidade são categorias fundamentais de entendimento.

É preciso nos perguntar sobre quais são os processos de definição da identidade, não vista aqui como categoria inata ao ser humano, ou como um dado, mas construída pelos processos sociais e psicológicos do ser (Ciampa, 2001). Trata-se de compreender os significados da identidade, os quais não se revelam só pela descrição, pela definição de classe social ou pelo conceito. $\mathrm{O}$ autor considera que: “....precisamos captar os significados implícitos, considerar o jogo das aparências, fundamentalmente com o desvelamento do que se mostra velado."

A temática aponta para a possibilidade da "metamorfose da identidade", que se explica tanto pelas condições objetivas quanto pelas subjetivas, num jogo ou embate contínuo entre se manter ou mudar o personagem, os quais nos são atribuídos, assumidos e/ou (re) construídos. A mudança seria suporte para o "ser-para-si e buscar a autodeterminação (que não é a ausência de determinações exteriores)”.

Dessa feita, não seria possível nomear a priori ou conceituar a situação aqui estudada, pois que é através da pesquisa e pela análise das falas dos vários personagens engendrados nessas tramas sociais e pela interpretação que a teoria apresenta, é que a reflexão tornaria mais próximo o conceito do real. Como afirma Lefebvre (1983), para o qual há uma veracidade relativa do conceito, o que exige reflexão incessante, para que o pensamento teórico, ao elevar as representações ao conceito, não as torne falso. 
Bibliografia

ALMEIDA, A. W. B. de. Os quilombos e as novas etnias. In: E. C. O’Dwyer. Quilombos: identidade étnica e territorialidade. São Paulo: ABA/FGV, 2002.

CARRIL, L. F. B. Terras de Negros no vale do Ribeira: Territorialidade e Resistência. Dissertação (Mestrado em História Social). FFLCH/USP, São Paulo, 1995.

CIAMPA, A. da C. A estória do Severino e A história da Severina. São Paulo: Brasiliense, 2001.

CUNHA, M. C. Antropologia do Brasil. Mito. História. Etnicidade. São Paulo: Brasiliense, 1987.

DIEGUES, A. C. O mito moderno da natureza intocada. São Paulo: Hucitec, 2001.

LEFEBVRE, H. La presencia y la ausencia. Contribución a la teoría de las representaciones. México: Fondo de Cultura economica, 1983.

MORAES, A. C. R. Território e História no Brasil. São Paulo: Annablume/Hucitec, 2002.

MOURA, C. Os quilombos e a rebelião negra. Tudo é História. São Paulo: Brasiliense, 1981.

RIBEIRO, D. Os índios e a civilização. A integração das populações indígenas no Brasil moderno. São Paulo: Companhia das Letras, 2000.

ROCHA, J., Domenich, Mirella e Casseano, P. Hip-Hop - A periferia grita. São Paulo: Fundação Perseu Abramo, 2001.

SACK, R. D. Human Territoriality. Its Teory and history. Cambridge: Cambridge University Press, 1986.

Santos, M. Nação ativa, nação passiva. Os verdadeiros agentes do futuro do país encontram-se entre os que estão sendo excluídos da contabilidade da globalização. "Brasil 500 d.C." Folha de São Paulo, São Paulo, 21 nov. 1999, Caderno Mais, p. 5-3. 